\title{
Effects of the circulating sheath currents in the magnetic field generated by an underground power line
}

\author{
J.R. Riba Ruiz ${ }^{1}$ X. Alabern Morera ${ }^{2}$ \\ ${ }^{1}$ Department d'Enginyeria Elèctrica, UPC \\ EUETII-"L'Escola d'Adoberia" \\ Plaça del Rei 15, 08700 Igualada (Spain) \\ phone:+34 938 035300, fax:+34 938 031589, e-mail: jordi@euetii.upc.edu \\ ${ }^{2}$ Department d'Enginyeria Elèctrica, UPC \\ C./ Colom 11, 08222 Terrassa (Spain) \\ phone: +34937398155, alabern@ee.upc.edu
}

\begin{abstract}
In this paper the influence of the metallic sheath in the magnetic field generated by underground single core power cables is studied. When dealing with underground power cables, sheath circulating currents can be induced. These currents produce power losses in the sheaths and decrease the ampacity (capacity of carrying current) of the cables. The circulating sheath currents generate a magnetic field that adds to the cable magnetic field. In this paper the modification of the total magnetic field is studied.
\end{abstract}

\section{Key words}

Magnetic field reduction, power cables, sheath currents, underground power lines.

\section{Introduction}

The raising environmental pressure is creating new markets for the power transmission systems based on very high voltage XLPE-isolated cables. Nowadays XLPE-cables are being applied up to $500 \mathrm{kV}$. In many countries high voltage overhead power lines are not allowed in large cities which are densely populated. These mentioned countries don't authorize overhead power lines in populated areas and promote the progressive burying of the existent overhead power lines in such areas. Catalunya is an example of this situation, and its government wants that in few years almost all the high voltage power lines in populated areas will be buried.

Therefore, it is not desirable an indiscriminate burying of the high voltage power lines. The burying of the power lines should be carried out mainly in populated and in ecological areas, whereas in rural areas the electric power lines should be overhead.

In this paper the influence of the metallic sheath in the magnetic field generated by underground single core power cables is studied. When dealing with underground power cables, sheath circulating currents can be induced. These currents produce power losses in the sheaths and decrease the ampacity (capacity of carrying current) of the cables. The circulating sheath currents generate a magnetic field that adds to the cable magnetic field. In this paper the modification of the total magnetic field is studied.

Figure 1 shows an underground power line installed in a service gallery.

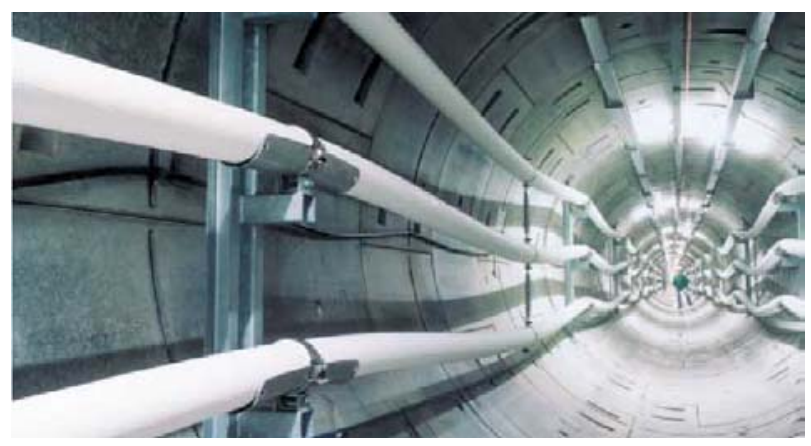

Figure 1. Underground power line

\section{Electric characteristics of the analyzed cables}

The high voltage cable studied in this work has the components shown in figure 2.

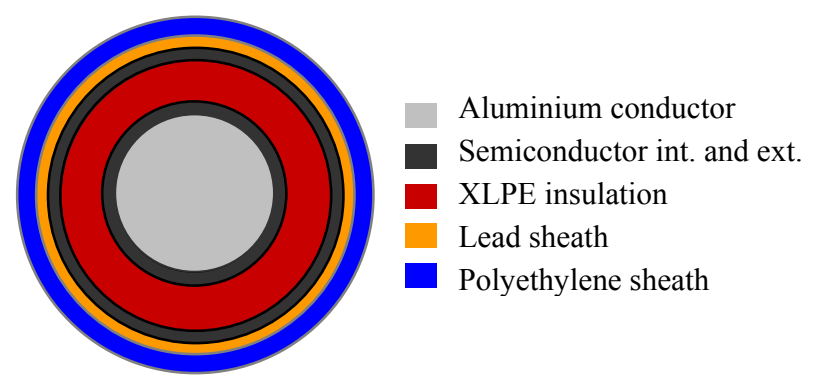

Figure 2. Diagram of a single core cable 
Table I shows the main characteristics of the high voltage studied cables.

TABLE I. Main characteristics of the single core $110 \mathrm{kV}$ cable under study

\begin{tabular}{lr}
\hline Conductor external diameter & $33,40 \mathrm{~mm}$ \\
Lead sheath mean diameter & $72,10 \mathrm{~mm}$ \\
Resistivity of the conductor $\left(20^{\circ} \mathrm{C}\right)$ & $4,69.10^{-5} \Omega / \mathrm{m}$ \\
Resistivity of the conductor $\left(70^{\circ} \mathrm{C}\right)$ & $5,64.10^{-5} \Omega / \mathrm{m}$ \\
Resistivity of the lead sheath & $5,23.10^{-4} \Omega / \mathrm{m}$ \\
$\left(20^{\circ} \mathrm{C}\right)$ & \\
Resistivity of the lead sheath & $6,06.10^{-4} \Omega / \mathrm{m}$ \\
$\left(60^{\circ} \mathrm{C}\right)$ & \\
External diameter of the cable & $83 \mathrm{~mm}$ \\
Number of strings of the conductor & 127 \\
Conductor size & $630 \mathrm{~mm}^{2}$ \\
Nominal voltage & $110 \mathrm{kV}$ \\
Admissible current & $750 \mathrm{~A}$ \\
\hline
\end{tabular}

\section{Power losses in the cables}

There are three main types of losses in underground power cables.

\subsection{Conductor losses}

The central conductor usually is made of copper or aluminium and it has a non negligible electrical resistance. In a presence of an electric current this resistance produces a heating of the cable. The central conductor resistance when dealing with alternate current is higher than when dealing with direct current. Therefore, the central conductor alternate current losses are higher than direct current losses. These losses can be written as:

$$
P_{\text {conductor }},_{A C}=I^{2} \cdot R_{A C} \cdot 10^{-3} \mathrm{~kW} / \mathrm{km}
$$

$R_{A C}$ should be expressed in $\Omega / \mathrm{km}$.

\subsection{Dielectric losses}

As shows figure 3, the structure conductor-insulationsheath acts as a cylindrical condenser. The total capacity of this condenser is given by:

$$
C=\frac{2 \cdot \pi \cdot \varepsilon_{0} \cdot \varepsilon_{r}}{\ln \left(r_{2} / r_{1}\right)} \mathrm{F} / \mathrm{m}
$$

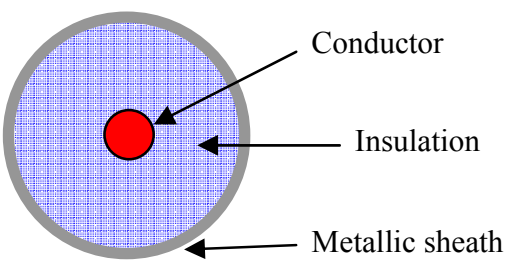

Figure 3. Structure conductor-insulation-sheath of a power cable

Dielectric losses become apparent as a dielectric heating, mainly due to the dielectric losses and the polarization losses. The origin of dielectric losses can be found in the fact that there isn't any perfect insulation, and all of them conduce very little. These losses are due to alternate and static electric fields.

The polarization losses are due to the polarization of a dielectric in the presence of an alternate electric field. The alternate electric field induces an orientation and disorientation of the dipoles, producing an internal friction that heats the dielectric. Static electric fields don't produce polarization losses.

The dielectric losses can be expressed as:

$$
\begin{gathered}
P_{\text {diel }}=2 . \pi . f . C \cdot U_{f}^{2} \cdot \operatorname{tg} \delta \\
Q_{\text {diel }}=P_{\text {diel }} \cdot \operatorname{tg} \delta
\end{gathered}
$$

$U_{f}$ : phase voltage $f$ : net frequency $C$ : cable capacity $\delta$ : dielectric losses angle

The reactive power consumption of underground power lines is between 20 and 40 times more than the reactive power consumption of overhead power lines. This fact decreases the active power carrying capacity of the underground line and forces to compensate the reactive power.

\section{Metallic sheath losses}

The metallic sheath is immerged in the magnetic field generated by the conductor current $I_{c}$. Therefore an induced voltage $e_{p}$ appears in the sheath, which induces currents in the metallic sheath. These currents dissipate energy due to Joule effect.

The induced voltage is maximum in the internal side of the sheath and minimum in its external side. This situation induces the circulation of eddy currents in the sheath. This is the origin of the eddy currents.

When neither extremes of the sheath are grounded, appears an induced voltage in the sheath which has a similar magnitude to the conductor voltage. This is a source of possible risks for maintenance personnel and also it facilitates possible perforations of the insulation due to sheath overvoltages.

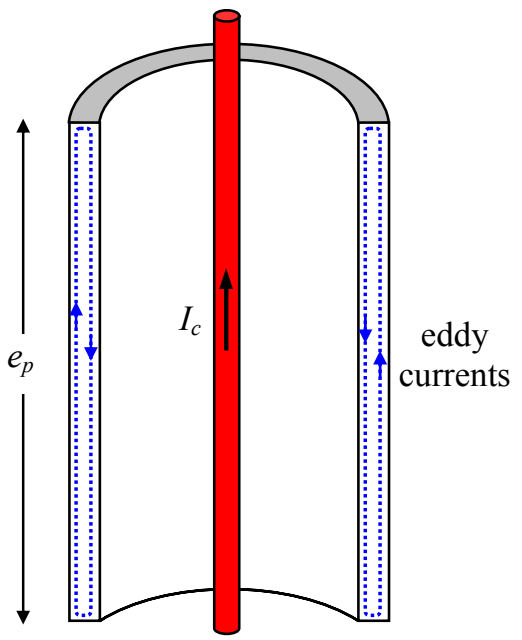


Figure 4. Not grounded metallic sheath

From the cross section of a power cable shown in figure 4 it is possible to understand the origin of the eddy currents in the sheath.

When both extremes of the sheath are grounded, the sheath $e_{p}$ tension induces a sheath circulating current $I_{p}$ along the sheath, which returns through the ground circuit. The circulating currents $I_{p}$ are usually much greater than the eddy currents. Therefore the eddy currents can be ignored when dealing with sheaths that have both extremes grounded.

Figure 5 shows the cross section of a power cable with the metallic sheath grounded at both ends.

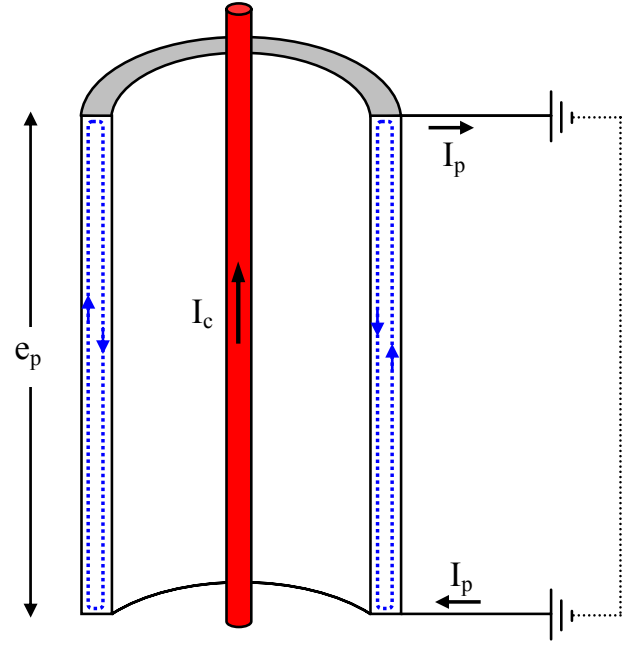

Figure 5. Sheath grounded in both extremes

When the sheath circulating currents and conductor currents are similar, the sheath acts as a quasi-perfect magnetic shield. The value of the sheath circulating current $I_{p}$ is independent of the cable length because of when the conductor length increases also increases the magnitude of the sheath induced voltage and the value of its electric impedance.

The circulating current in the sheath increases with the physical gap among conductors of the three phase circuit.

\section{Sheath bonding methods}

When the sheaths of single-conductor cables are bonded to each other, as is common practice for multiconductor cables, the induced voltage causes current to flow in the completed circuit. This current generates losses in the sheaths. Various methods of bonding may be used for the purpose of minimizing sheath losses. Formerly, where special bonding was employed for the prevention of sheath losses on lead-sheathed cables without an insulating jacket, the sheaths were subjected to ac voltages, and the bonding was designed to keep the magnitude of the induced voltages within small limits so as to prevent the possibility of sheath corrosion due to ac electrolysis.

\subsection{Single-point bounding}

It is the simplest system of bonding and it is shown in figure 6 . The metallic sheaths are grounded at only one point along their length. At all other points, a voltage will appear from sheath to ground that will be a maximum at the farthest point from the ground bond. Since there is no closed sheath circuit current no sheath circulating current loss occurs, but sheath eddy loss will still be present.

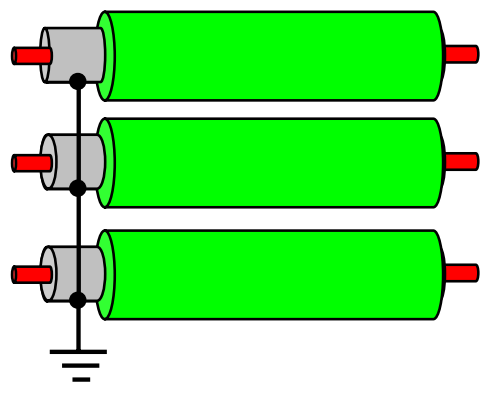

Figure 6. Single-point bonding

\subsection{Multiple-point bonding}

The metallic sheaths are grounded at least at the two extremes of the cable, as shown in figure 7. This system doesn't allow high values of the induced voltages in the metallic sheaths. When dealing with multiple-point bonding cables, sheath circulating current loss occurs because there is a closed circuit current. This is the system studied in this paper.

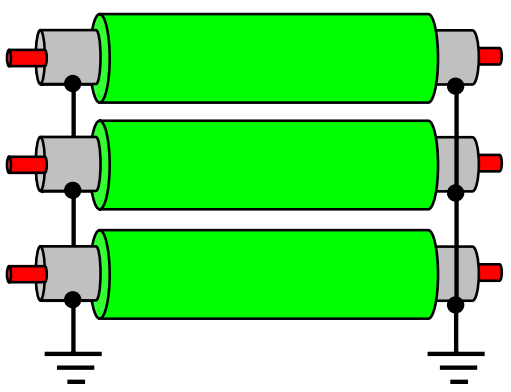

Figure 7. Multiple-point bonding

The circulating currents produce different effects:

- Circulating sheath currents generate power losses by heating.

- Circulating sheath currents reduce the cables ampacity (current flow capacity) due to thermal effects.

- Circulating sheath currents generate a magnetic field that adds to the cable magnetic field. In this paper the modification of the total magnetic field is studied.

\section{Computation of the sheath currents and the magnetic fields generated by the power line}

We have assumed two three-phase power line geometries, trefoil and plain configurations.

From the geometry of the line and the electric and geometric parameters of the cables, the sheath circulating currents are computed from equations given in IEC 287- 
1-1 publication. By adding the sheath circulating current with the central conductor current in each cable we have computed the total magnetic field generated by the cable.

\subsection{Trefoil formation}

Figure 8 shows the geometry of a line in trefoil configuration.

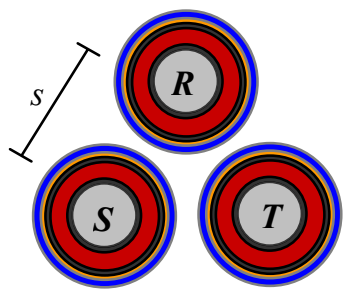

Figure 8. Trefoil formation

We have calculated the circulating sheath intensities in two situations, for $s=0,083 \mathrm{~m}$ (external diameter of the cable) and for $s=0,166 \mathrm{~m}$ (two times the external diameter of the cable).

Table II shows the currents in the central conductor and in the sheaths when dealing with $s=0,083 \mathrm{~m}$.

TABLE II. Currents for $s=0,083 \mathrm{~m}$

\begin{tabular}{cc}
\hline & Electric current in Ampers \\
Cable R & $750+\mathrm{j} .0$ \\
Cable S & $-375-\mathrm{j} .649,52$ \\
Cable T & $-375+\mathrm{j} .649,52$ \\
Sheath of cable R & $-5,558-\mathrm{j} .64,325$ \\
Sheath of cable S & $-52,928+\mathrm{j} .36,976$ \\
Sheath of cable T & $58,487+\mathrm{j} .27,349$ \\
\hline
\end{tabular}

Figure 9 shows the magnetic field intensities, computed in the straight line placed in the vertical of the central conductor axis for three cables without and with metallic sheath.

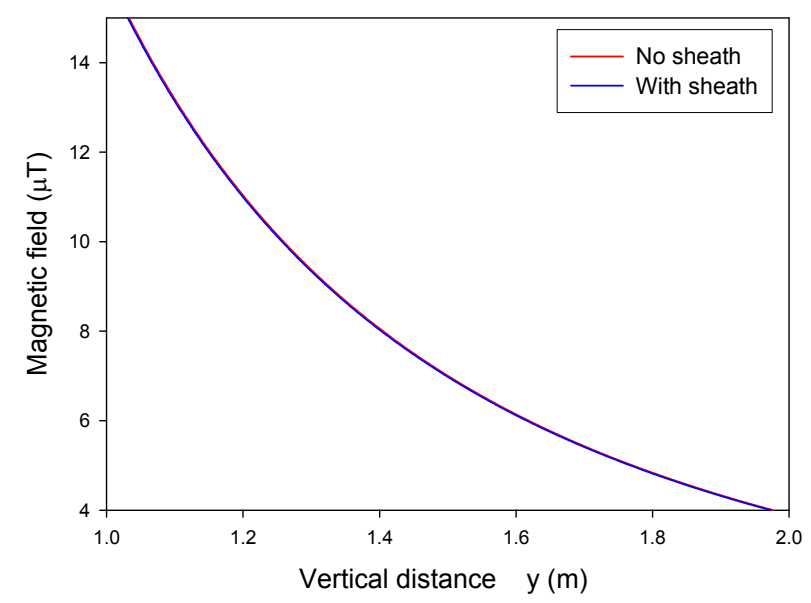

Figure 9. Magnetic field generated by the trefoil formation with $\mathrm{s}=0,083 \mathrm{~m}$

As shown in figure 9, the line with sheathed cables generates a magnetic field that is a $0,37 \%$ lower that the magnetic field created by the un-sheathed line.
Table III shows the currents in the central conductor and in the sheaths when dealing with $s=0,166 \mathrm{~m}$.

TABLE III. Currents for $s=0,166 \mathrm{~m}$

\begin{tabular}{cc}
\hline & Electric current in Ampers \\
Cable R & $750+\mathrm{j} .0$ \\
Cable S & $-375-\mathrm{j} .649,52$ \\
Cable T & $-375+\mathrm{j} .649,52$ \\
Sheath of cable R & $-18,318-\mathrm{j} .115,77$ \\
Sheath of cable S & $-91,103+\mathrm{j} .73,750$ \\
Sheath of cable T & $109,42+\mathrm{j} .42,022$ \\
\hline
\end{tabular}

Figure 10 shows the magnetic field intensities, computed in the straight line placed in the vertical of the central conductor axis for three cables without and with metallic sheath.

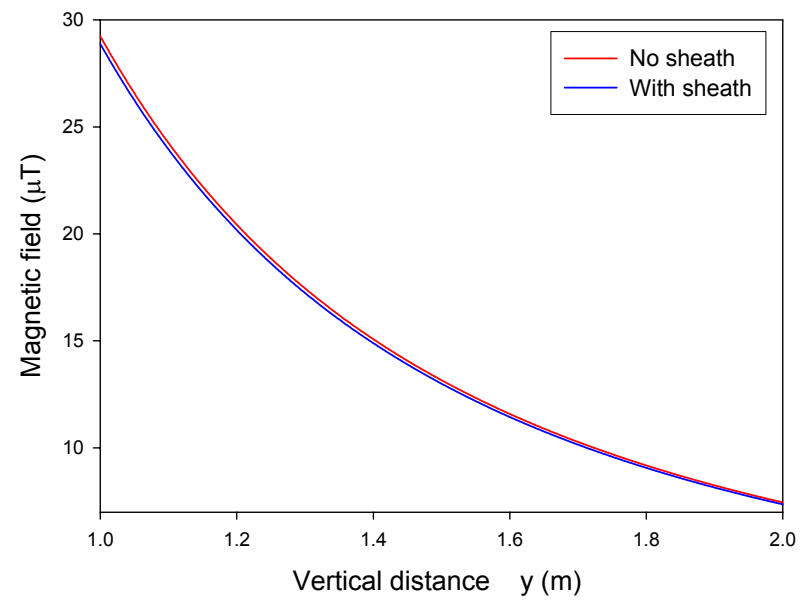

Figure 10. Magnetic field generated by the trefoil formation $\mathrm{s}=0,166 \mathrm{~m}$

As shown in figure 10, the line with sheathed cables generates a magnetic field that is a $1,23 \%$ lower that the magnetic field created by the un-sheathed line.

\subsection{Flat formation}

Figure 11 shows the geometry of a line in trefoil configuration.

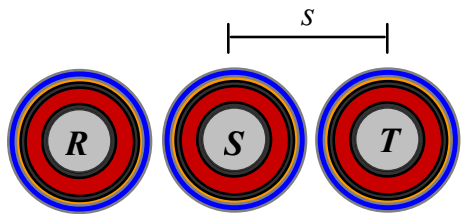

Figure 11. Flat formation

Table IV shows the currents in the central conductor and in the sheaths when dealing with $s=0,083 \mathrm{~m}$.

TABLE IV. Currents for $s=0,083 \mathrm{~m}$

\begin{tabular}{cc}
\hline & Electric current in Ampers \\
Cable R & $750+\mathrm{j} .0$ \\
Cable S & $-375-\mathrm{j} .649,52$ \\
Cable T & $-375+\mathrm{j} .649,52$ \\
Sheath of cable R & $-44,390-\mathrm{j} .91,827$ \\
Sheath of cable S & $-38,959+\mathrm{j} .25,859$ \\
Sheath of cable T & $83,349+\mathrm{j} .65,968$ \\
\hline
\end{tabular}


Figure 12 shows the magnetic field intensities, computed in the straight line placed in the vertical of the central conductor axis for three cables without and with metallic sheath.

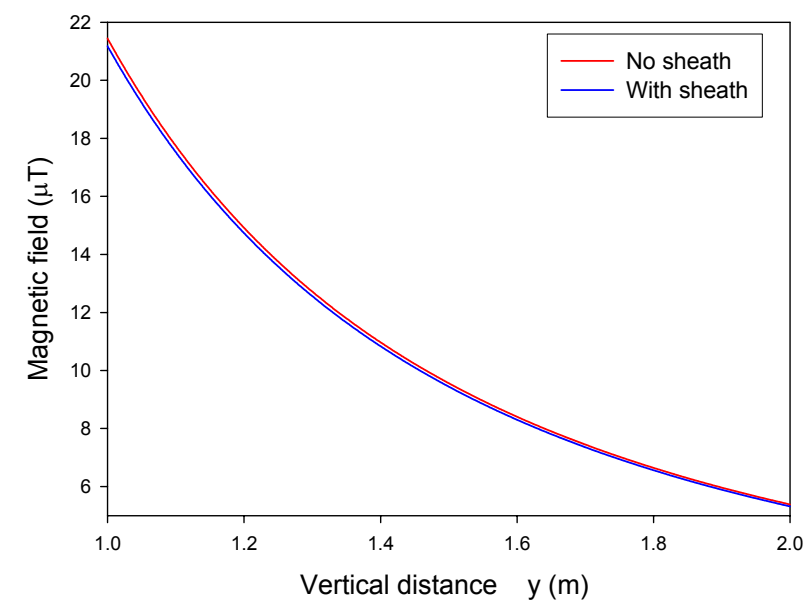

Figure 12. Magnetic field generated by the flat formation with $\mathrm{s}=0,083 \mathrm{~m}$

As shown in figure 9, the line with sheathed cables generates a magnetic field that is a $1,22 \%$ lower that the magnetic field created by the un-sheathed line.

Table V shows the currents in the central conductor and in the sheaths when dealing with $s=0,166 \mathrm{~m}$.

TABLE V. Currents for $s=0,166 \mathrm{~m}$

Cable R
Cable S
Cable T

Sheath of cable R

Sheath of cable $\mathrm{S}$

Sheath of cable T

Figure 13 shows the magnetic field intensities, computed in the straight line placed in the vertical of the central conductor axis for three cables without and with metallic sheath.

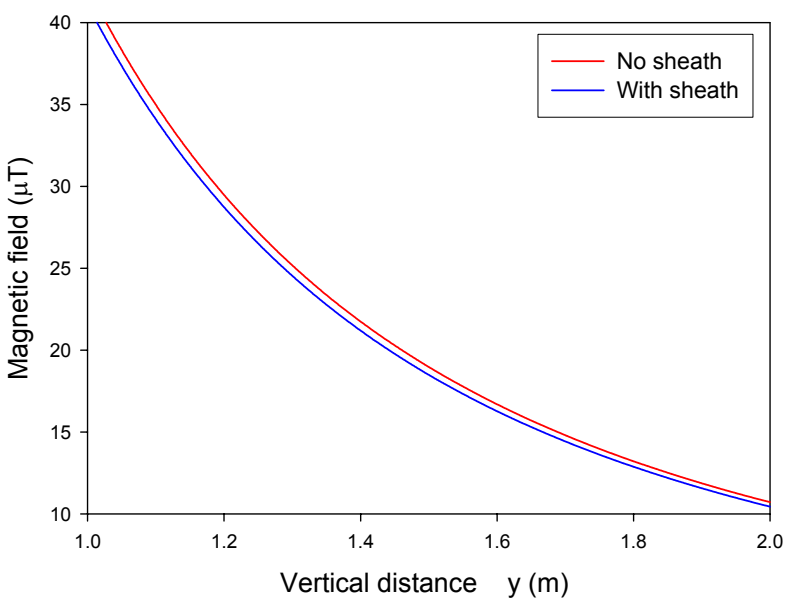

Figure 13. Magnetic field generated by the flat formation with $\mathrm{s}=0,166 \mathrm{~m}$
As shown in figure 9, the line with sheathed cables generates a magnetic field that is a $2,48 \%$ lower that the magnetic field created by the un-sheathed line.

\section{Conclusions}

Once the study has been realized, the following conclusions can be deduced:

- It has been shown that the geometry of the line, the gap between conductors and the electric and geometric parameters of the conductors have an important effect on the circulating sheath currents values.

- The circulating currents create a magnetic field which adds to the magnetic field generated by the central conductor. The resultant magnetic field usually is lower than the magnetic field generated by the central conductor.

- The reduction factor of the magnetic field depends on the geometry of the power line and the electric parameters of the cable.

- When the gap between the axes increases, also increase the sheath circulating currents. This fact produces a higher reduction of the total magnetic field generated by the power line.

\section{References}

[1] IEC 287-1-1: "Electric cables-calculation of the current rating, part 1: current rating equations (100\% load factor) and calculation of losses, section 1: general". IEC publication 287, 1994.

[2] ANSI/IEEE Std 575-1 988, IEEE Guide for the Application of Sheath-Bonding Methods for SingleConductor Cables and the Calculation of Induced Voltages and Currents in Cable Sheaths.

[3] J.S. Barrett, G.J.Anders. "Circulating current and hysteresis losses in screens, sheaths and armour of electric power cables-mathematical models and comparison with IEC Standard 287". IEE Proc.-Sei. Meas. Technol., Vol. 144, No. 3, pp. 101-110, May 1997

[4] Peter Graneau. "Underground power transmission. The science, technology \& economics of high voltage cables”. Ed. John Wiley \& Sons, 1979.

[5] Manuel Llorente Antón. "Cables eléctricos aislados. Descripción y aplicaciones practices". Editorial Paraninfo, 1994..

[6] Víctor Sierra Madrigal, Alfonso Sansores Escalante. "Manual técnico de cables de energía". Ed. Mc Graw Hill, 2a Edición, 1984

[7] Enrique Ras. "Teoría de líneas eléctricas". Ed. Marcombo 1986

[8] Jordi-Roger Riba, Xavier Alabern. "Experimental behavior of a magnetic field shield for an underground power line". Internacional Conference on Renewable Energy and Power Quality. Zaragoza, 2005. 